\title{
Ethical and Legal Perspective of Software Piracy and Business Effects on the Illegal Use of Peer-to-Peer Systems Architecture
}

\author{
Lemuel Magno Ventayen \\ Pangasinan State University, Alaminos Campus \\ Bolaney, Alaminos City \\ Pangasinan, Philippines
}

\author{
Randy Joy Magno Ventayen \\ Pangasinan State University, Lingayen Campus \\ Poblacion, Lingayen \\ Pangasinan, Philippines
}

\begin{abstract}
This is descriptive survey research aims to investigate the ethical and legal perspective of software piracy and use of P2P Systems architecture. It sought to answer the profile of the respondents regarding the program, age and year level of the respondents, the attitudes of the respondents regarding software piracy and the attitudes of the respondents regarding the use of Peer to Peer Systems Architecture. The respondents are also asked about the reason for using the $\mathrm{P} 2 \mathrm{P}$ and pirate software. The result of the respondent's shows that majority of the respondents agree that software piracy is acceptable. While most of the respondents agree that piracy is accepted, most of the respondents sometimes practice piracy because of the high cost of content and respondents does not want to pay for it. Based on the result, it is recommended that content providers should increase the security of content to avoid loss of profit..
\end{abstract}

\section{General Terms}

Peer-to-peer (P2P) systems architecture is a distributed application architecture that partitions tasks or workloads between peers, there is no server between peers.

\section{Keywords}

$\mathrm{P} 2 \mathrm{P}$, business ethics, legal practices

\section{INTRODUCTION}

Due to the increasing technological advantage, acquiring information is more accessible than before, and piracy becomes a subject of great interest in the past years. P2P applications and more specifically BitTorrent, an application that is being daily used by millions of users [1], Today's reality is that BitTorrent is one of the most used protocols on top of Tor (with HTTP/HTTPS) in terms of traffic size and number of connections [2], and it is the commonly used P2P systems architecture for piracy.

The researcher would like to know if there are changes in attitude from the older generation up to the millennials. Several studies conducted regarding software piracy since the 1980s. Christoph, Forcht, and Bilbrey published a study in 1987 and concluded that prior computer knowledge made no significant difference in their attitudes toward piracy [3]. Cohen and Cornwell also replicated the study by Christoph et al. last 1989 and added additional questions asking respondents whether they had engaged in software piracy and whether they consider it legal. [4]

\subsection{Statement of the Problem}

This study will answer the following question. (1) What is the profile of the respondents regarding program, age and year level of the respondents? (2) What are the attitudes of the respondents regarding software piracy (3) What are the attitudes of the respondents regarding the use of Peer to Peer Systems Architecture? (4) What is the respondent's reason for using P2P and pirate software, if any?

The scope of the study does not include the correlation between the attitude of respondents regarding software piracy and use of the Peer to Peer Systems Architecture and the profile variables. It is recommended in the future paper that will discuss the significant difference between the attitude of the respondents across the practice of the respondents towards piracy and use of P2P Systems Architecture

\section{P2P SYSTEMS ARCHITECHTURE}

Unlike in other patterns, peers play a vital role in P2P. Peers are equally privileged, and equal participants in the application. Peers are said to form a peer-to-peer network of nodes. To define the architecture itself, Peer-to-peer (P2P) systems architecture is a distributed application architecture that partitions tasks or workloads between peers, there is no server between peers.

In this literature review, the proponent looked at the limitations and advantage of the systems architecture pattern and where it is applicable. Client/Server Architecture is well known, powerful and reliable server is a data source, while $\mathrm{C} / \mathrm{S}$ Architecture is used in file sharing, several limitations have been recorded such as the use of traffic, P2P Systems addressed several limitations. Since clients are also servers and routers, $\mathrm{P} 2 \mathrm{P}$ Computing shared its resources directly to the peer, these resources and services include the exchange of information, processing cycles, cache storage and disk storage for files [14]. P2P computing takes advantage of existing computing power, storage, and network connectivity, allowing users to leverage their collective power to the benefit of all.

Despite the advantage of $\mathrm{P} 2 \mathrm{P}$, too many people believed, the use of Peer to Peer or specifically the BitTorrent client is synonymous with piracy. [5] If P2P systems architecture will shut down, many content creators would have the scramble to look for alternatives. Like HTTP, which browsers use to communicate or connect to a website, $\mathrm{P} 2 \mathrm{P}$ and BitTorrent is just a protocol. HTTP and FTP can also download pirated content just as we can do with $\mathrm{P} 2 \mathrm{P}$, but $\mathrm{P} 2 \mathrm{P}$ is probably primarily used for uploading and downloading unauthorized content. Many organization used BitTorrent client as a way to update software such as game update; it uses the build in BitTorrent client in the game launchers to automatically downloads it for us. Even Facebook and Twitter used BitTorrent to transfer large files from each server [6] to 
propagate large files over a large number of different servers. Technically based on the sources, P2P is not illegal, it is just a protocol for data transfer. However, how come the perception of many to $\mathrm{P} 2 \mathrm{P}$ is illegal? It is because of its probably primary use for downloading an illegal content because it is unmonitored for decentralized P2P.

Typically, the majority of $\mathrm{P} 2 \mathrm{P}$ traffic is related to copyrighted material [7] and other files. This is to conclude that sharing of files is legal, but sharing a copyrighted file without authorization is illegal. Legality always depends on the user itself.

\section{METHODOLOGY}

Some part of the questionnaire used was adopted from the study of Cohen and Conwell [4]. Instead of using the questionnaire as is, the proponent modifies the question and added several questions relating to the use of Peer to Peer to achieve the result of the study. The respondents were also asked about their attitude and usage about privacy, and the use of others. They were not asked to categorize themselves by race or any identifying information, but the program, sex and year level was included in determining if there is a relationship. To maintain the anonymous of the respondents, personal information was remove in the survey questionnaire.

Google forms were used to float the questionnaire. The respondents are the students of one state university from 3 campuses mostly are Business Administration students and Information Technology Students. Convenience sampling was used in determining the respondents, it is is a non-probability sampling technique where subjects are selected not only because of their convenient accessibility and proximity to the researcher but to determine if there is a significant relationship across the course or program of the student. Questionnaires were numbered after collection too, and the answers were tabulated using a spreadsheet.

\section{RESULTS AND DISCUSSION}

The result answers only the profile of the respondents regarding the program, age and year level, the attitudes of the respondents regarding software piracy, the attitudes of the respondents regarding the use of Peer to Peer Systems Architecture, and the respondent's reason of using the P2P and pirate software.

Based on the Profile of the respondents, there are $65 \%$ female and $35 \%$ male, Majority of the respondents are 19 years old with $48.3 \%$ followed by 20 years old with $16.7 \%$ and $11.7 \%$ for 18 years of age.

\subsection{Attitudes of Respondents in Software Piracy and Peer to Peer usage}

Based on the result of the survey, $53.45 \%$ of the respondents agree that software piracy is okay. While $42.92 \%$ does not agree on piracy. It is visualized in the table below the attitudes of the respondents in a statement shown below. Those statement with more than 50 percent who agree is marked in red to emphasize the result of the majority.

Table 1: Attitudes of Students in Software Piracy

\begin{tabular}{|c|c|c|c|c|c|c|}
\hline Statement & Yes & & No & & & ure \\
\hline I think it is okay... [for people such as myself to copy commercial software instead of buying it.] & 49 & $81.67 \%$ & 9 & $15.0 \%$ & 2 & $3.3 \%$ \\
\hline $\begin{array}{l}\text { I think it is okay... [for people such as myself to copy commercial software instead of buying it when we } \\
\text { use it for educational purposes.] }\end{array}$ & 50 & $83.33 \%$ & 9 & $15.0 \%$ & 1 & $1.7 \%$ \\
\hline I think it is okay... [to use another student's computer account without the student's knowledge.] & 3 & $5.00 \%$ & 56 & $93.3 \%$ & 1 & $1.7 \%$ \\
\hline I think it is okay... [for a user to use the University's computer for non-University activities.] & 9 & $15.00 \%$ & 46 & $76.7 \%$ & 5 & $8.3 \%$ \\
\hline I think it is okay... [for a student to look at, but not change, confidential student records.] & 15 & $25.00 \%$ & 39 & $65.0 \%$ & 6 & $10.0 \%$ \\
\hline I think it is okay... [for a student to look at and change confidential student records.] & 9 & $15.00 \%$ & 49 & $81.7 \%$ & 2 & $3.3 \%$ \\
\hline I think it is okay... [for students to work together on individual computer assignments.] & 36 & $60.00 \%$ & 22 & $36.7 \%$ & 2 & $3.3 \%$ \\
\hline I think it is okay... [for students to give a copy of their work to another student to hand in.] & 19 & $31.67 \%$ & 35 & $58.3 \%$ & 6 & $10.0 \%$ \\
\hline $\begin{array}{l}\text { I think it is okay... [for two students to share the work for a computer assignment and each hand in a } \\
\text { copy.] }\end{array}$ & 33 & $55.00 \%$ & 25 & $41.7 \%$ & 2 & $3.3 \%$ \\
\hline I think it is okay... [for a user to copy commercial software for personal use and share it with others.] & 35 & $58.33 \%$ & 23 & $38.3 \%$ & 2 & $3.3 \%$ \\
\hline I think it is okay... [to download commercial software from Torrent and use Crack to use it] & 23 & $38.33 \%$ & 34 & $56.7 \%$ & 3 & $5.0 \%$ \\
\hline I think it is okay... [to copy software and install it on my computer with crack or keygen.] & 22 & $36.67 \%$ & 34 & $56.7 \%$ & 4 & $6.7 \%$ \\
\hline $\begin{array}{l}\text { I think it is okay... [to watch downloaded movies rather than to watch in the cinema or buy the original } \\
\text { movie.] }\end{array}$ & 48 & $80.00 \%$ & 12 & $20.0 \%$ & 0 & $0.0 \%$ \\
\hline I think it is okay... [to use torrent and another P2P client to download entertainment] & 26 & $43.33 \%$ & 27 & $45.0 \%$ & 7 & $11.7 \%$ \\
\hline I think it is okay... [to copy movies from others electronic media (such as HD or SDcards)] & 52 & $86.67 \%$ & 7 & $11.7 \%$ & 1 & $1.7 \%$ \\
\hline I think it is okay... [to copy music from others electronic media (such as HD or SDcards)] & 53 & $88.33 \%$ & 7 & $11.7 \%$ & 0 & $0.0 \%$ \\
\hline I think it is okay... [to ask my friend or myself to send me movie thru my mobile unit] & 50 & $83.33 \%$ & 9 & $15.0 \%$ & 1 & $1.7 \%$ \\
\hline I think it is okay... [to ask my friend or myself to send me music thru my mobile unit] & 50 & $83.33 \%$ & 10 & $16.7 \%$ & 0 & $0.0 \%$ \\
\hline $\begin{array}{l}\text { I think it is okay... [to download research paper and use the copy-paste method and submit to my } \\
\text { teacher/instructor.] }\end{array}$ & 19 & $31.67 \%$ & 38 & $63.3 \%$ & 3 & $5.0 \%$ \\
\hline I think it is okay... [to copy from the website and other online resources for my project.] & 32 & $53.33 \%$ & 24 & $40.0 \%$ & 4 & $6.7 \%$ \\
\hline
\end{tabular}


It is visible in the figure that Software Piracy is acceptable as visualized in the figure. The blue marks agreement that software piracy in the statement is acceptable. This shows that majority of the respondent's attitude towards software piracy and uses to P2P illegally is still acceptable.
The result of the study supports the evidences from study of Acilar [17] that many undergraduate students consider software piracy and other unethical use of information technologies as an acceptable behavior. It is also observed by the researcher that most of the students stored music in there laptop and mobile device but didn't paid for the content.

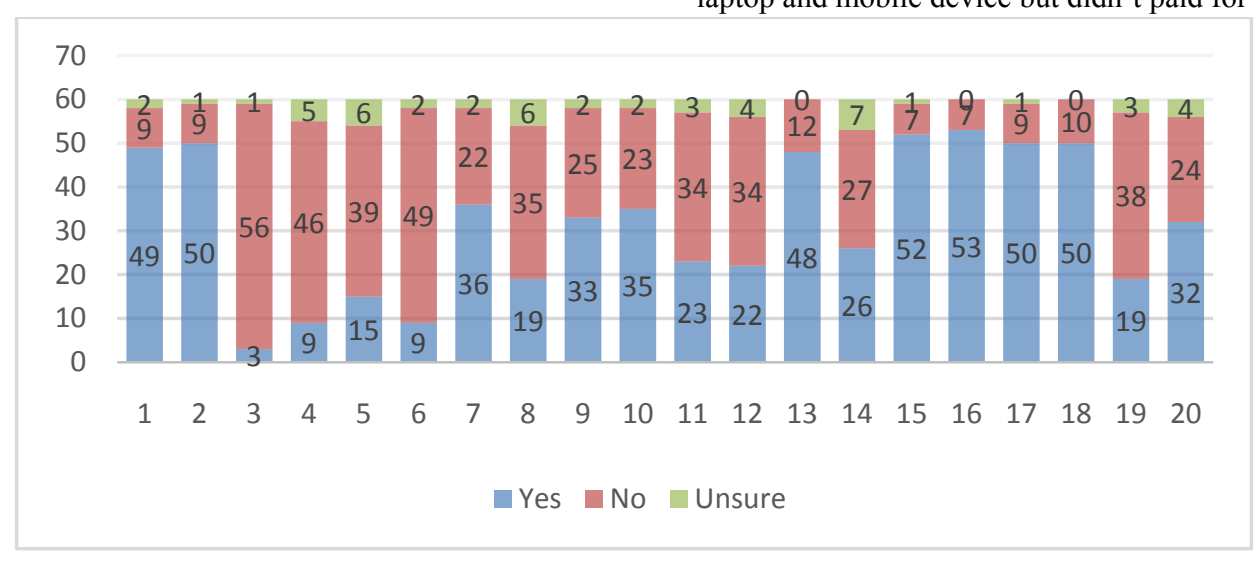

Figure 1: Distribution of Attitude in Software Piracy

\subsection{Practices of Respondents in Software Piracy and Peer to Peer usage}

Despite a high agreement in software piracy, only $27.60 \%$ of the respondents are always practicing software piracy. While
$39.90 \%$ sometimes do illegal actions. There is an average of $32.5 \%$ of the respondents are not practicing piracy. It is visualized in the table below the practice of the respondents. Those statement with more than 50 percent who agree is marked in red to emphasize the result.

Table 2: Practice of Students in Software Piracy

\begin{tabular}{|c|c|c|c|c|c|c|}
\hline \multirow{2}{*}{$\begin{array}{l}\text { Statement on Practice. } \\
\text { I tried to... [copy commercial software instead of buying it.] }\end{array}$} & \multicolumn{2}{|c|}{ Always } & \multicolumn{2}{|c|}{ Sometimes } & \multicolumn{2}{|c|}{ Never } \\
\hline & 24 & $40.00 \%$ & 26 & $43.33 \%$ & 10 & $16.67 \%$ \\
\hline I tried to... [copy commercial software instead of buying and use it for educational purposes.] & 27 & $45.00 \%$ & 23 & $38.33 \%$ & 10 & $16.67 \%$ \\
\hline I tried to... [use another student's computer account without the student's knowledge.] & 5 & $8.33 \%$ & 10 & $16.67 \%$ & 45 & $75.00 \%$ \\
\hline I tried to... [use the University's computer for non-University activities.] & 8 & $13.33 \%$ & 16 & $26.67 \%$ & 36 & $60.00 \%$ \\
\hline I tried to... [look at, but not change, confidential student records.] & 6 & $10.00 \%$ & 16 & $26.67 \%$ & 38 & $63.33 \%$ \\
\hline I tried to... [look at and change confidential student records.] & 5 & $8.33 \%$ & 10 & $16.67 \%$ & 45 & $75.00 \%$ \\
\hline I tried to... [work together on individual computer assignments.] & 12 & $20.00 \%$ & 38 & $63.33 \%$ & 10 & $16.67 \%$ \\
\hline I tried to... [give a copy of their work to another student to hand in.] & 7 & $11.67 \%$ & 38 & $63.33 \%$ & 15 & $25.00 \%$ \\
\hline I tried to... [share the work for a computer assignment and each hand in a copy.] & 9 & $15.00 \%$ & 36 & $60.00 \%$ & 15 & $25.00 \%$ \\
\hline I tried to... [copy commercial software for personal use and share it with others.] & 15 & $25.00 \%$ & 30 & $50.00 \%$ & 15 & $25.00 \%$ \\
\hline I tried to... [download commercial software from Torrent and use Crack to use it] & 7 & $11.67 \%$ & 26 & $43.33 \%$ & 27 & $45.00 \%$ \\
\hline I tried to... [copy software and install it on my computer with crack or keygen.] & 13 & $21.67 \%$ & 17 & $28.33 \%$ & 30 & $50.00 \%$ \\
\hline I tried to... [watch downloaded movies rather than to watch in the cinema or buy the original movie.] & 32 & $53.33 \%$ & 21 & $35.00 \%$ & 7 & $11.67 \%$ \\
\hline I tried to... [use torrent and another P2P client to download entertainment] & 13 & $21.67 \%$ & 21 & $35.00 \%$ & 26 & $43.33 \%$ \\
\hline I tried to... [copy movies from others electronic media (such as HD or SDcards)] & 29 & $48.33 \%$ & 26 & $43.33 \%$ & 5 & $8.33 \%$ \\
\hline I tried to... [copy music from others electronic media (such as HD or SDcards)] & 32 & $53.33 \%$ & 24 & $40.00 \%$ & 4 & $6.67 \%$ \\
\hline I tried to... [ask my friend or myself to send me movie thru my mobile unit] & 30 & $50.00 \%$ & 24 & $40.00 \%$ & 6 & $10.00 \%$ \\
\hline I tried to... [ask my friend or myself to send me music thru my mobile unit] & 31 & $51.67 \%$ & 25 & $41.67 \%$ & 4 & $6.67 \%$ \\
\hline $\begin{array}{l}\text { I tried to... [download research paper and use the copy-paste method, and submit to my } \\
\text { teacher/instructor.] }\end{array}$ & 11 & $18.33 \%$ & 25 & $41.67 \%$ & 24 & $40.00 \%$ \\
\hline I tried to... [copy from the website and other online resources for my project.] & 15 & $25.00 \%$ & 27 & $45.00 \%$ & 18 & $30.00 \%$ \\
\hline
\end{tabular}


It is visible in the figure 2 that Software Piracy is still practiced as visualized in the figure. The blue marks are always practicing software piracy. This shows that majority of the respondent's practice software piracy and uses to P2P illegally sometimes.

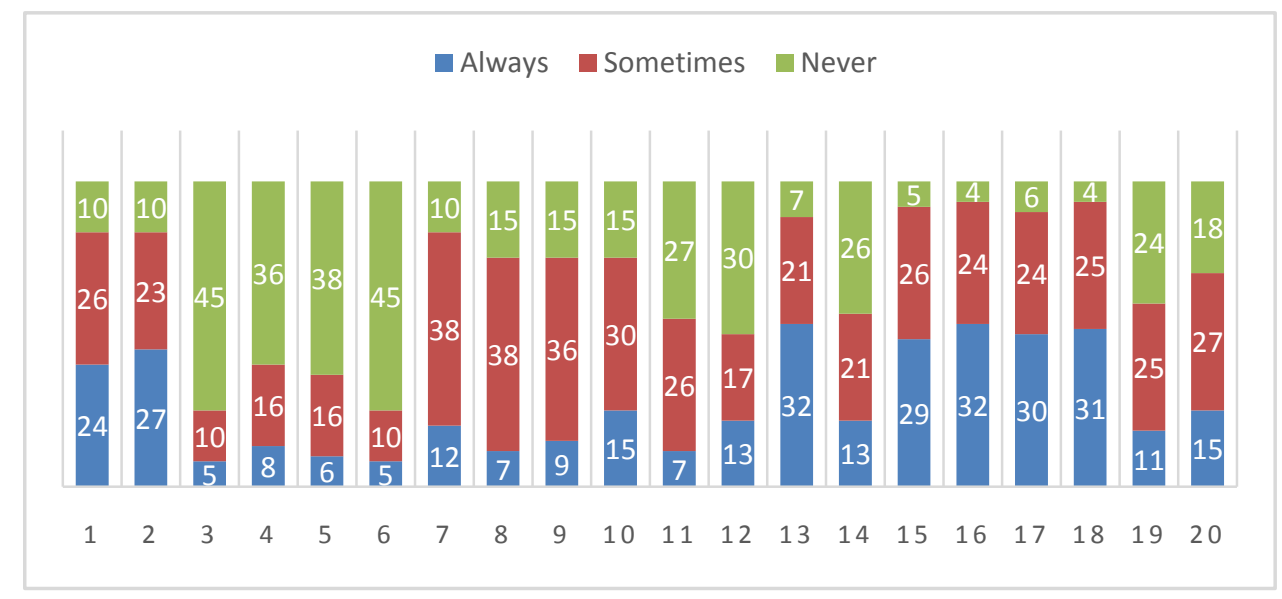

Figure 2: Distribution of Practice in Software Piracy

Based on the figure 3, the higher the level of the attitude, the higher the level the practice. The relationship between the attitude and practice shows that student will more likely to practice the statement if the respondents believe that it is okay. The result support the study of Ming, et.al. that personality traits are said to be an effective positive influence on unethical behavior. [18]

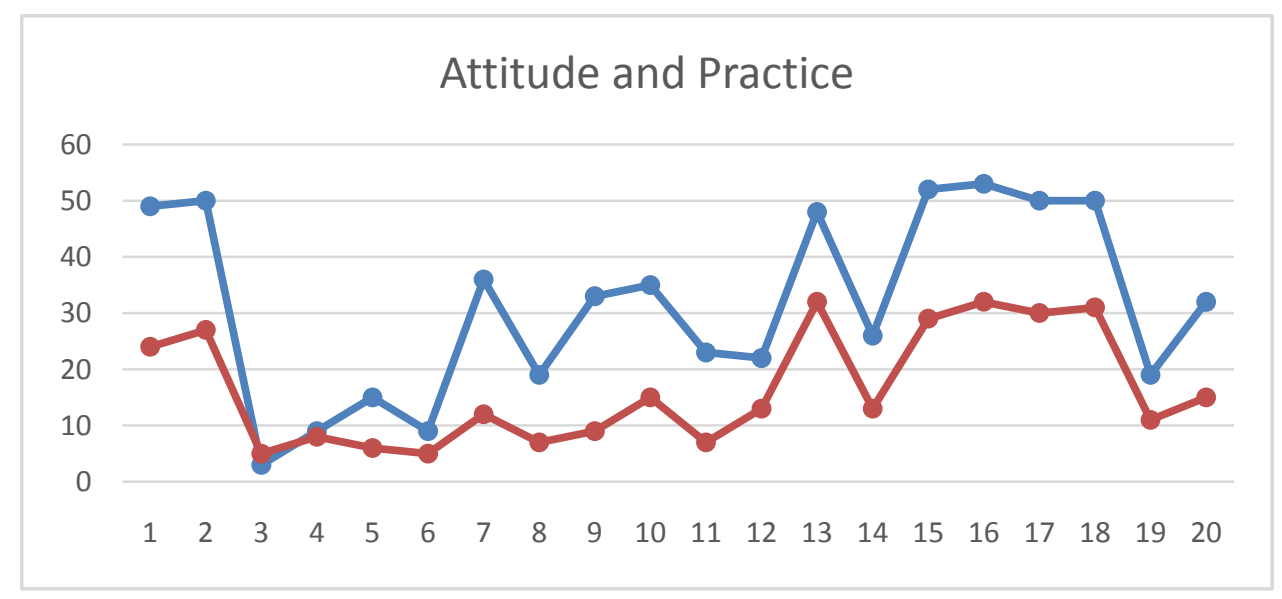

Figure 3: Graphical Relationship between Attitude and Practice

\subsection{The reason of the Respondents in using piracy}

Based on the result of the survey, $80 \%$ of the respondents practice piracy because they can't afford the content. Followed by $48.3 \%$ with the reason that the respondents don't like to pay for it. 35\% of the respondents find it hard to purchase, and $21.7 \%$ says that "others are doing it too." It shows that the main reason for piracy is the respondents cannot afford original content and doesn't want to invest money in the content. The result of the study implies that the estimated losses for the software industry are approaching more than $\$ 60$ billion [15], thus the main reason why software industry failed to earn money is because the users doesn't want to spend for the content, in this regard, the only way to avoid losses is to fight piracy [16].

\subsection{Effects of Piracy in Business and Ethics}

Piracy hurt the business industry so much, it does not only affect the profit of an organization, but it also affects the ethical perspective and practice of human. While the business of the software company vendors and content creator are the victim of the growing epidemic, [9] manufacturing company are also affected. In this study, it investigates the practice and attitude of the respondents to determine the impact in the business world and provide a recommendation.

Another practice that is visible in the Philippines is internet hacking. It is an act of accessing the internet without paying for service. In a global study called Digital in 2018 [11], Most of the Filipino spent an average of 3 hours and 57 minutes every day on social media in the year 2017. Users have grown by $27 \%$ in the past year. The Philippines is known as the texting capital of the world [9], and also a social media capital of the world [10]. It is widespread in the Philippines that internet users are selling VPN to access the internet illegally. Virtual Private Network [12] itself is legal because it provides users an anonymously use of the network, while the telecom in the Philippines forbid the use of such network illegally. There are some reports from one telecom in the Philippines for such entrapment operation of illegal sellers of modified network modems as an illegal modus operandi [13]. Despite the fact that authority imposed a cybercrime law in the 
country, it is still a challenge to aim for its full implementation.

\section{CONCLUSION AND RECOMMENDATION}

The study shows a relationship between the attitude of respondents regarding software piracy and use of the Peer to Peer Systems Architecture. It is visible in the result that software piracy is acceptable from the respondents, and the higher the level of attitude, the higher the level of practice. It is concluded that despite the acceptability of software piracy, money is still the main reason why respondents are practicing piracy. There is no reason that piracy is acceptable in the field of business and technology. The researcher may conclude that security imposed by the developers are the only solution to avoid software piracy. Thus it is recommended that developers and business owners should maximize the security of their content to avoid the pirated copy

\section{ACKNOWLEDGMENTS}

Our thanks to Dr. Nova Arquilano, the Coordinator of Research in PSU Lingayen Campus for allowing us to present this paper in the campus in-house proposal review.

\section{REFERENCES}

[1] Stevens Le Blond, Arnaud Legout, Fabrice Le Fessant, Walid Dabbous, and Mohamed Ali Kaafar. Spying the World from your Laptop - Identifying and Pro?ling Content Providers and Big Downloaders in BitTorrent. In 3rd USENIX Workshop on Large-Scale Exploits and Emergent Threats (LEET'10), San Jose, CA the United States, 2010. Usenix.

[2] Damon McCoy, Kevin Bauer, Dirk Grunwald, Tadayoshi Kohno, and Douglas Sicker. Shining light in dark places: Understanding the tor network. In In Privacy Enhancing Technologies Symposium 2008 (PETS), 2008.

[3] Christoph, R., Forcht, K., \& Bilbrey, C. (1987). The development of information systems ethics: An analysis. Journal of Computer Information Systems, 28(2), 20-23.

[4] Eli Cohen and Larry Cornwell, "College Students Believe Piracy is Acceptable", CIS Educator Forum: A Quarterly Journal. 1(3) March 1989, p. 2-5.

[5] Karunaratne, S. B. (2012). The Case Against Combating BitTorrent Piracy Through Mass John Doe Copyright Infringement Lawsuits. Michigan Law Review, 283-309.

[6] BitTorrent behind Facebook and Twitter. (2015, July 11). Retrieved November 25, 2017, from http://www.labortech.net/bittorrent-behind-facebookand-twitter/

[7] Karagiannis, T., Broido, A., Brownlee, N., Claffy, K. C., \& Faloutsos, M. (2004, November). Is p2p dying or just hiding?[p2p traffic measurement]. In Global Telecommunications $\quad$ Conference, 2004 GLOBECOM'04. IEEE (Vol. 3, pp. 1532-1538). IEEE.

[8] The Hidden Cost Of Software Piracy In The Manufacturing Industry. (2016). Manufacturing Business Technology. Retrieved 3 May 2018, from https://www.mbtmag.com/article/2016/02/hidden-costsoftware-piracy-manufacturing-industry

[9] Ellwood-Clayton, B. (2006). All we need is love-and a mobile phone: Texting in the Philippines. Cultural Space and Public Sphere in Asia, Seoul, Korea.

[10] Infographic Angela Salano, A. (2017). PH vs the World: Internet and social media penetration. ABS-CBN News. Retrieved 3 May 2018, from http://news.abscbn.com/focus/multimedia/infographic/10/16/17/ph-vsthe-world-internet-and-social-media-penetration

[11] Digital in 2018: World's internet users pass the 4 billion mark - We Are Social. (2018). We Are Social. Retrieved 3 May 2018, from https://wearesocial.com/blog/2018/01/global-digitalreport-2018

[12] Larson, V., Short III, R. D., Munger, E. C., \& Williamson, M. (2015). U.S. Patent No. 9,094,399. Washington, DC: U.S. Patent and Trademark Office.

[13] Illegal sellers of hacked Globe WiMAX modems arrested in Nueva Ecija (2018). Retrieved 3 May 2018, from https://www.globe.com.ph/press-room/illegalsellers-of-hacked-globe-wimax

[14] An Introduction To Peer-to-peer Networks. (n.d.) Retrieved from http://www.eecg.toronto.edu/ jacobsen/mie456/slides/p2 p-mie.pdf

[15] Moores, T., \& Dhillon, G. (2000). Software piracy: A view from Hong Kong. Communications of the ACM, 43(12), 88-93.

[16] Asongu, S. A. (2015). Fighting software piracy in Africa: how do legal origins and IPRs protection channels matter?. Journal of the Knowledge Economy, 6(4), 682703.

[17] Acilar, A. (2010). Demographic factors affecting freshman students' attitudes towards software piracy: An empirical study. Issues in Informing Science and Information Technology, 7(8), 321-328.

[18] Ming, T. M., Jabar, M. A., Wei, K. T., \& Sidi, F. (2015, December). A preliminary study of personality traits and their influence on software piracy. In Software Engineering Conference (MySEC), 2015 9th Malaysian (pp. 252-258). IEEE. 